stammte. Da aber die Art auf Carduus lebt, so kann sie natürlich nicht an die Küste gebunden sein und auch in Österreich, Griechenland und Algier wurde sie weit von der Küste gefunden. Ganz unbegreiflich ist, warum Oschanin Proserpinae in die Gattung Orthotylus stellt, denn aus der Beschreibung geht ja sofort hervor, daß die Art unmöglich ein Orthotylus sein kann.

\title{
Cryptostemmatidae.
}

13. Die Gattung Cryptostemma H. Sch. wurde, wie Oschanin richtig angibt, 1835 errichtet und ist älter als die Arachniden-Gattung Cryptostemma Guér. (1838). Nach F i ebers Angabe wäre der Name bei den Coleopteren vergeben, aber dies ist nicht der Fall. Dipsocoris Hal. ist deshalb synonym zu Cryptostemma H. Sch.

\section{Zwei sehr bemerkenswerte neue Varietäten von Tetrix Kraussi Saulcy.}

Von Dr. Bernhard Haij, Leksand, Schweden.

(Mit 2 Textfiguren.)

Tetrix Kraussi ist meiner Ansicht nach eine Art, die in lebhafter Formbildung begriffen ist. In einer früheren Arbeit $(\mathrm{Om}$ de svenska formerna af släktet Tetrix Latr., Entomol. Tidskrift, Stockholm 1909) habe ich auf die große Variabilität aufmerksam gemacht, die die obengenannte Art auszeichnet, und habe ich fünf Formen getrennt und beschrieben, die hauptsächlich durch die verschiedenen Entwicklungsgrade des Processus Pronoti und der Hinterflügel charakterisiert sind. Ich erlaube mir nun auf einige weitere eigentümliche Varietäten aufmerksam zu machen, die bis dahin nicht beobachtet worden sind.

\section{Tetrix Kraussi v. paradoxa m. (Fig. 1.)}

Von der typischen Form durch folgendes verschieden:

Area lateralis anterior Processus Pronoti ist außerordentlich groß und breit, bedeckt zum größten Teile die Elytra (und die Hinterflügel). Die Seitenloben des Pronotum haben einen einzigen Einschnitt im Hinterrande, der obere Einschnitt fehlt vollständig; die Pronotum-Seiten sind daher einlappig wie bei den Larven. - Diese Varietät besitzt ein spezielles 
Interesse, da sie eine Form darstellt, die betreffs der Entwicklung: des Pronotum auf dem Larvenstadium stehen geblieben ist. Sie ist aber von der Larve leicht zu unterscheiden, sowohl durch die allgemeine Form des Pronotum und die Länge des Processus, als auch durch die normal ausgebildeten Elytra und Hinterflügel und durch

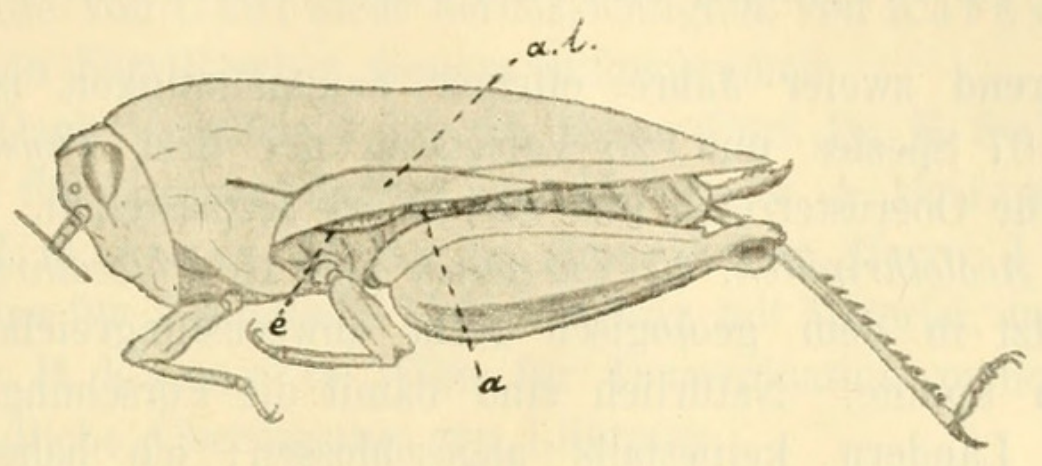

Fig. 1.

die bei allen Tetrix-Formen im ausgebildeten Zustande vorkommenden Einschnitte im oberen Rande, dicht an der Spitze der Hinterschenkel. Tetrix Kraussi v. paradoxa hat nichts mit dem von Fieber beschriebenen Tetrix Schrankii zu schaffen, welcher ohne Zweifel nur als eine Larvenform aufzufassen ist.

In Härjedalen (mittleres Schweden) von mir gefunden.

\section{Tetrix Kraussi v. tuberculata m. (Fig. 2.)}

Stimmt mit der typischen Form genau überein, unterscheidet sich jedoch durch folgendes:

Das Pronotum ist sehr rauh und höckerig; der

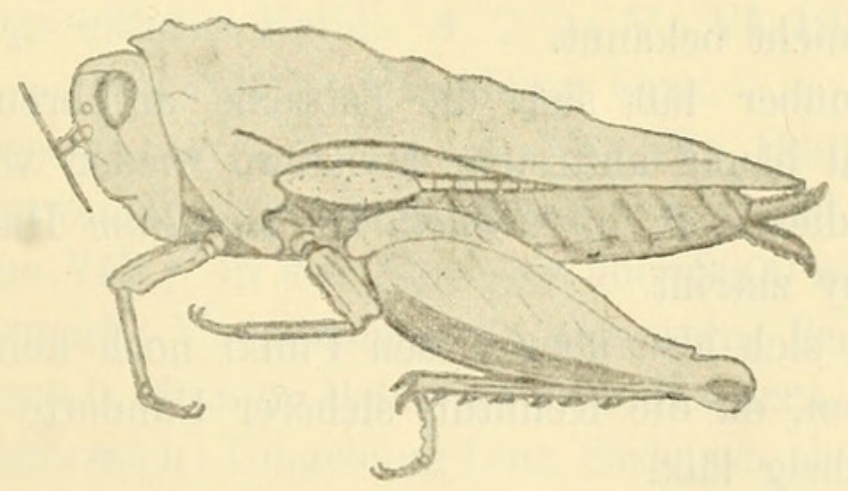

Fig. 2.

Rückenkiel ist deutlich unduliert, vorn mit stumpfen abgerundeten Zähnen versehen.

Auch diese Varietät habe ich in Härjedalen (mittleres Schweden) gefunden. 


\section{$2 \mathrm{BHL}$ Biodiversity Heritage Library}

Haij, Bernhard Julius. 1914. "Zwei sehr bemerkenswerte neue Varietäten von Tetrix Kraussi SAULEY." Wiener entomologische Zeitung 33, 184-185. https://doi.org/10.5962/bhl.part.17794.

View This Item Online: $\underline{\text { https://www.biodiversitylibrary.org/item/42670 }}$

DOI: https://doi.org/10.5962/bhl.part.17794

Permalink: https://www.biodiversitylibrary.org/partpdf/17794

\section{Holding Institution}

Smithsonian Libraries

\section{Sponsored by}

Smithsonian

\section{Copyright \& Reuse}

Copyright Status: NOT_IN_COPYRIGHT

This document was created from content at the Biodiversity Heritage Library, the world's largest open access digital library for biodiversity literature and archives. Visit BHL at https://www.biodiversitylibrary.org. 